INTERVENTIONAL CARDIOLOGY AND SURGERY

\title{
The CP stent-short, long, covered-for the treatment of aortic coarctation, stenosis of pulmonary arteries and caval veins, and Fontan anastomosis in children and adults: an evaluation of 60 stents in 53 patients
}

\author{
P Ewert, S Schubert, B Peters, H Abdul-Khaliq, N Nagdyman, P E Lange
}

Heart 2005;91:948-953. doi: 10.1136/hrt.2004.040071

See end of article for authors' affiliations

.....................

Correspondence to:

Dr Peter Ewert, Abteilung

für Angeborene

Herzfehler, Deutsches

Herzzentrum Berlin,

Augustenburger Platz 1

13353 Berlin, Germany;

ewerł@dhzb.de

Accepted 27 August 2004

\begin{abstract}
Objective: To evaluate the feasibility and usefulness of the Cheatham platinum (CP) stent in a broad spectrum of lesions.

Methods: Retrospective analysis of 60 implanted CP stents (11-80 mm lengths, 12 covered) between September 2001 and March 2004.

Patients: 53 patients aged 2.5-68 years (median 17 years). Body weight ranged from 12-95 kg (median $52 \mathrm{~kg}$ ). Thirty six patients had aortic (re)coarctation; seven of them had functionally interrupted aortic arches. Thirteen patients had pulmonary artery stenosis and four had stenosis of caval veins or conduits in a total cavopulmonary connection (TCPC).

Results: Arterial pressure gradients dropped from $33 \mathrm{~mm} \mathrm{Hg}$ (range $20-80 \mathrm{~mm} \mathrm{Hg}$ ) to $5 \mathrm{~mm} \mathrm{Hg}$ (range 0-10 $\mathrm{mm} \mathrm{Hg}$ ) and pressure gradients in TCPC or caval veins dropped from $4 \mathrm{~mm} \mathrm{Hg}$ (range 4$20 \mathrm{~mm} \mathrm{Hg}$ ) to $0 \mathrm{~mm} \mathrm{Hg}$ (range $0-3 \mathrm{~mm} \mathrm{Hg}$ ). All stents were placed in the target lesion without complications. Three stent fractures without clinical instability were noted.

Conclusions: The CP stent is suitable for the treatment of vessel stenosis in congenital heart diseases from childhood to adulthood. Whether these good results will be stable in the long term needs to be investigated.
\end{abstract}

$\mathrm{S}$ tent implantation for the treatment of vessel stenosis in congenital heart diseases is a field of increasing importance in transcatheterisation. ${ }^{1-24}$ However, only a few stents are available that can be dilated to large diameters of $20 \mathrm{~mm}$ or beyond. The Cheatham platinum (CP) stent (NuMED Inc, Hopkinton, New York, USA) is especially designed for the treatment of vascular obstructions associated with congenital heart diseases. ${ }^{25}$ It has achieved certification for the European market (CE mark) and is now commercially available. We report our experience with this stent gathered in a preliminary study.

\section{PATIENTS AND METHODS}

Patients

Between September 2001 and March 2004, 60 CP stents were implanted in 53 patients at our institution. Patients' ages ranged from 2.5-68 years (median 17 years). Body weight ranged from 12-95 kg (median $52 \mathrm{~kg}$ ).

Thirty six patients had coarctation or recoarctation of the aorta. Seven of them had functionally interrupted aortic arches. Thirteen patients had pulmonary artery stenosis and three patients had stenosis of the caval veins or the conduit in a total cavopulmonary connection (TCPC). In one patient, a connection through an extracardiac polytetrafluoroethylene (PTFE) conduit into the right atrium was created as a partial take down of a total cavopulmonary anastomosis.

Table 1 lists detailed demographic data and diagnoses.

\section{Stent}

In contrast to the majority of balloon expandable stents, which are cut by laser from a metal tube, the CP stent is manufactured from wire of a platinum-iridium alloy. The wire is bent and welded to a cylindrical meshwork, forming the stent. All stents used in this study were so called " 8 zig" stents-that is, eight diamond shaped meshes form the circumference. In the unexpanded state one mesh is $11 \mathrm{~mm}$ long; thus, the shortest stent is $11 \mathrm{~mm}$ long. By welding further segments together in longitudinal direction, the stent can be manufactured to every desired length in increments of $6 \mathrm{~mm}$. The recommended minimum dilated diameter is $8 \mathrm{~mm}$ and the maximum diameter is $24 \mathrm{~mm}$ accompanied by a foreshortening of $20 \%$. However, dilatation to larger diameters is possible. For more detailed information see Cheatham 2001. ${ }^{25}$ From December 2002 onwards, the stent was produced with reinforced gold brazes.

Every stent is available with an expanded PTFE membrane, which is attached to the outer side of the stent.

\section{Stent implantation}

The study was approved by the locally appointed ethics committee and, before stent implantation, informed consent was received from the patients or their parents. A diagnostic catheterisation was performed to determine the exact morphology and the pressure gradient of the stenosis. In aortic coarctations and pulmonary artery stenosis a systolic pressure gradient of $20 \mathrm{~mm} \mathrm{Hg}$ or more was considered an indication for stent implantation. In the systemic veins and a TCPC circulation, a residual pressure gradient of $4 \mathrm{~mm} \mathrm{Hg}$ after an attempt at balloon dilatation was the criterion for stent placement. In two patients with a TCPC, a stent was implanted to improve blood flow in the presence of a morphological stenosis.

To enable exact stent placement, all interventions were performed through a long sheath. The access site was the femoral artery for coarctations and femoral veins for the

Abbreviations: CP, Cheatham platinum; TCPC, total cavopulmonary connection; PTFE, polytetrafluoroethylene 
Table 1 Demographic data of 53 patients treated with 60 Cheatham platinum (CP) stents

\begin{tabular}{|c|c|c|c|c|c|c|c|c|c|c|}
\hline \multirow[b]{2}{*}{ Patient } & \multirow{2}{*}{$\begin{array}{l}\text { Age } \\
\text { (years) }\end{array}$} & \multirow{2}{*}{$\begin{array}{l}\text { Body } \\
\text { weight } \\
\text { (kg) }\end{array}$} & \multirow[b]{2}{*}{ Diagnosis } & \multirow[b]{2}{*}{ Implantation site } & \multicolumn{2}{|c|}{$\begin{array}{l}\text { Pressure gradient } \\
(\mathrm{mm} \mathrm{Hg})\end{array}$} & \multirow{2}{*}{$\begin{array}{l}\text { CP stent } \\
\text { length } \\
(\mathrm{mm})\end{array}$} & \multirow{2}{*}{$\begin{array}{l}\text { ePTFE } \\
\text { covered } \\
\text { stent }\end{array}$} & \multirow{2}{*}{$\begin{array}{l}\text { Maximum } \\
\text { dilatation } \\
(\mathrm{mm})\end{array}$} & \multirow{2}{*}{$\begin{array}{l}\text { Sheath size } \\
\text { (French) }\end{array}$} \\
\hline & & & & & Before SI & After SI & & & & \\
\hline 1 & 2.5 & 15 & Re-Coa after SI & Coa & 25 & 10 & 22 & No & 10 & 9 \\
\hline 2 & 2.7 & 15 & Native Coa & Coa & 45 & 8 & 16 & No & 10 & 8 \\
\hline 3 & 3 & 14 & Native Coa & Coa & 60 & 5 & 22 & No & 10 & 8 \\
\hline 4 & 4 & 12 & $\begin{array}{l}\text { Re-Coa after balloon } \\
\text { angioplasty }\end{array}$ & Coa & 30 & 0 & 22 & No & 10 & 7 \\
\hline 5 & 6 & 17 & $\begin{array}{l}\text { Re-Coa after balloon } \\
\text { angioplasty }\end{array}$ & Coa & 45 & $15^{*}$ & 16 & No & 12 & 7 \\
\hline 6 & 6 & 18 & TAC, IAA, Coa after surgery & Coa & 23 & $15 \dagger$ & 16 & No & 10 & 8 \\
\hline 7 & 7 & 22 & Native Coa & Coa & 30 & 0 & 34 & No & 14 & 11 \\
\hline 8 & 8 & 24 & Re-Coa after surgery & Coa & 30 & 10 & 11 & No & 12 & 9 \\
\hline 9 & 8 & 28 & Native subatretic Coa & Coa & 60 & $25 \dagger$ & 28 & Yes & 10 & 10 \\
\hline 10 & 9 & 33 & $\begin{array}{l}\text { Re-Coa after balloon } \\
\text { angioplasty }\end{array}$ & Coa & 30 & 5 & 28 & No & 14 & 10 \\
\hline 11 & 10 & 56 & Re-Coa after surgery & Coa & 20 & 5 & 28 & No & 12 & 10 \\
\hline 12 & 10 & 34 & Native Coa & Coa & 30 & $8 \dagger$ & 39 & No & 16 & 11 \\
\hline 13 & 10 & 41 & $\begin{array}{l}\text { Re-Coa after balloon } \\
\text { angioplasty }\end{array}$ & Coa & 30 & 0 & 39 & No & 18 & 12 \\
\hline 14 & 10 & 53 & Native Coa & Coa & 50 & 0 & 28 & No & 18 & 12 \\
\hline 15 & 11 & 50 & $\begin{array}{l}\text { Re-Coa after balloon } \\
\text { angioplasty }\end{array}$ & Coa & 30 & 0 & 28 & No & 16 & 11 \\
\hline 16 & 11 & 38 & Native Coa & Coa & 30 & 10 & 28 & No & 14 & 10 \\
\hline 17 & 12 & 54 & $\begin{array}{l}\text { Re-Coa after balloon } \\
\text { angioplasty }\end{array}$ & Coa & 35 & 5 & 34 & No & 12 & 9 \\
\hline 18 & 13 & 34 & Re-Coa after surgery & Coa & 45 & 5 & 16 & No & 14 & 9 \\
\hline 19 & 14 & 50 & Re-Coa after surgery & Coa & 30 & 0 & 39 & No & 16 & 11 \\
\hline 20 & 17 & 68 & Native Coa & Coa & 20 & 0 & 28 & No & 18 & 12 \\
\hline 21 & 17 & 48 & Native Coa & Coa & 30 & 5 & 22 & No & 16 & 10 \\
\hline 22 & 18 & 86 & Native Coa & Coa & 45 & $5 \dagger$ & 50 & Yes & 12 & 12 \\
\hline 23 & 21 & 51 & Re-Coa after surgery & Coa & 25 & 0 & 22 & No & 14 & 12 \\
\hline 24 & 22 & 65 & $\begin{array}{l}\text { VSD, Eisenmenger, re-Coa } \\
\text { after surgery and stent }\end{array}$ & Coa & 60 & $10+$ & 39 & Yes & 12 & 14 \\
\hline 25 & 25 & 54 & Re-Coa after surgery & Coa & 30 & 0 & 39 & No & 14 & 11 \\
\hline 26 & 27 & 65 & Re-Coa after surgery & Coa & 40 & 10 & 39 & No & 16 & 12 \\
\hline 27 & 34 & 70 & Native subatretic Coa & Coa & 50 & 0 & 28 & No & 16 & 11 \\
\hline 28 & 39 & 57 & Native subatretic Coa & Coa & 70 & 0 & 39 & Yes & 14 & 12 \\
\hline 29 & 39 & 83 & $\begin{array}{l}\text { Re-Coa with aneurysm after } \\
\text { surgery }\end{array}$ & Coa aneurysm & 30 & $15+$ & 80 & Yes & 22 & 12 \\
\hline 30 & 40 & 95 & Native Coa & Coa & 80 & 0 & 39 & No & 25 & 12 \\
\hline 31 & 40 & 69 & Native subatretic Coa & Coa & 70 & 10 & 39 & Yes & 14 & 12 \\
\hline 32 & 49 & 78 & Native subatretic Coa & Coa & 55 & 0 & $39 / 39 \ddagger$ & Yes/yes & 18 & 14 \\
\hline 33 & 51 & 75 & $\begin{array}{l}\text { Re-Coa after balloon } \\
\text { angioplasty }\end{array}$ & Coa & 20 & 10 & 39 & Yes & 18 & 12 \\
\hline 34 & 54 & 55 & Native subatretic Coa & Coa & 20 & 0 & 39 & Yes & 25 & 14 \\
\hline 35 & 64 & 72 & Native Coa & Coa & 35 & 0 & 39 & Yes & 20 & 13 \\
\hline 36 & 67 & 52 & Native subatretic Coa & Coa & 40 & $5 \dagger$ & 39 & Yes & 18 & 14 \\
\hline 37 & 22 & 78 & TAC, homograft stenosis & PA & 45 & $5 \dagger$ & 34 & No & 16 & 12 \\
\hline 38 & 18 & 43 & $\begin{array}{l}\mathrm{Pa}+\mathrm{VSD} \text {, unifocalisation, } \\
\text { LPA stenosis after surgery }\end{array}$ & LPA & 20 & 6 & 22 & No & 14 & 11 \\
\hline 39 & 32 & 74 & Hypoplastic LPA & LPA & 35 & $20 \dagger$ & 22 & No & 10 & 11 \\
\hline 40 & 36 & 71 & $\begin{array}{l}\text { TGA, VSD, PS, Rastelli, LPA } \\
\text { stenosis after BT shunt }\end{array}$ & LPA & 50 & 5 & 28 & No & 25 & 11 \\
\hline 41 & 55 & 60 & TOF after surgery & LPA & 40 & 0 & 34 & No & 14 & 11 \\
\hline 42 & 12 & 34 & TAC, homograft & RPA & 60 & 5 & 22 & No & 14 & 11 \\
\hline 43 & 14 & 44 & TOF, conduit & RPA/LPA/PA & 30 & 0 & $34 / 28 / 28$ & No & $14 / 14 / 16$ & 11 \\
\hline 44 & 15 & 42 & TGA, post-ASO, RPA stenosis & RPA & 65 & 10 & 28 & No & 12 & 10 \\
\hline 45 & 32 & 57 & $\begin{array}{l}\mathrm{Pa}+\text { VSD, unifocalisation, } \\
\text { LPA stenosis after surgery }\end{array}$ & RPA & 20 & 10 & 28 & No & 10 & 9 \\
\hline 46 & 34 & 75 & TOF, heterograft & RPA/LPA & $60 / 40$ & $0 / 0$ & $39 / 28$ & No & 16 & 11 \\
\hline 47 & 56 & 72 & Native stenosis & RPA/LPA & 60 & $10 / 0$ & $28 / 28$ & No & 16 & 12 \\
\hline 48 & 6 & 18 & $\begin{array}{l}\text { Pa without VSD, hypoplastic } \\
\text { RV, TCPC }\end{array}$ & LPA & 4 & 0 & 16 & No & 12 & 9 \\
\hline 49 & 15 & 40 & $\begin{array}{l}\text { TGA, VSD, hypoplastic RV, } \\
\text { TCPC }\end{array}$ & VCl-RA/RA-PA & MS & O NMS & $34 / 28$ & No & $22 / 22$ & 12 \\
\hline 50 & 16 & 31 & Tricuspid atresia, TCPC & RPA & 4 & 0 & 28 & No & 10 & 9 \\
\hline 51 & 34 & 64 & DORV, mitral atresia, TCPC & TCPC conduit & MS & ONMS & 39 & No & 18 & 10 \\
\hline 52 & 68 & 65 & $\mathrm{VCl}$ stenosis by tumour & & 20 & 3 & $34 / 34$ & No & 18 & 12 \\
\hline 53 & 8 & 19 & DILV, failing Fontan & $\begin{array}{l}\text { Extracardiac conduit/ } \\
\text { RA }\end{array}$ & NA & NA & 16 & No & 12 & 13 \\
\hline
\end{tabular}

${ }^{*}$ Caused by a hypoplastic segment in the aortic arch; †second, definitive dilatation pending; timplantation of a second stent because of fracture of the first one. ASO, atrial switch operation; BT, Blalock-Taussig; Coa, coarctation of the aorta; DILV, double inlet left ventricle; DORV, double outlet right ventricle; ePTFE, expanded polytetrafluoroethylene; IAA, interrupted aortic arch; LPA, left pulmonary artery; MS, morphological stenosis; NA, not available; NMS, no morphological stenosis, Pa, pulmonary atresia; PA, pulmonary artery; PS, pulmonary stenosis; RPA, right pulmonary artery; Sl, stent implantation; RV, right ventricle; TAC, truncus arteriosus communis; TCPC, total cavopulmonary connection; TGA, d-transposition of the great arteries; TOF, tetralogy of Fallot; VCI, inferior caval vein; VSD, ventricular septal defect. 

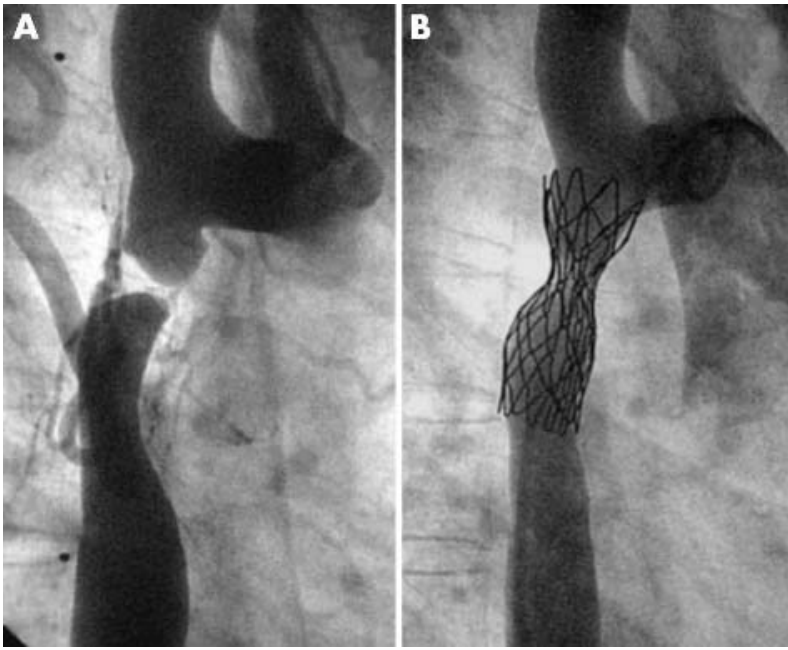

remaining stenoses. One stent was placed through the internal jugular vein because of thrombosis of the femoral veins, and one stent was implanted into a coarctation through the femoral vein and a ventricular septal defect because of bilateral thrombosis of the iliac arteries. In patients with coarctation and a body weight of more than $25 \mathrm{~kg}$, a single stitch suture device was applied to the femoral artery (6 French; The Closure, Perclose, Redwood City, California, USA). Before insertion of the larger implantation sheath, the device was placed, leaving the knot open until the long sheath was definitively removed at the end of the procedure. The CP stent requires a 2 French larger sheath than is necessary for the dilatation balloon and, in the case of a PTFE covered stent, a 3 French larger sheath is needed. The stents were crimped on an appropriate balloon, either manually or in the case of low profile balloons (5-7 French) with a crimping device (Qualimed, Winsen/Luhe, Germany). After advancement of the mounted stent to the stenotic vessel through the sheath, manual injection of dye through the sheath or angiographies by means of a separate access confirmed the desired position of the stent immediately before implantation. In cases of severe stenosis the procedure was performed in two steps with the definitive dilatation six months later.
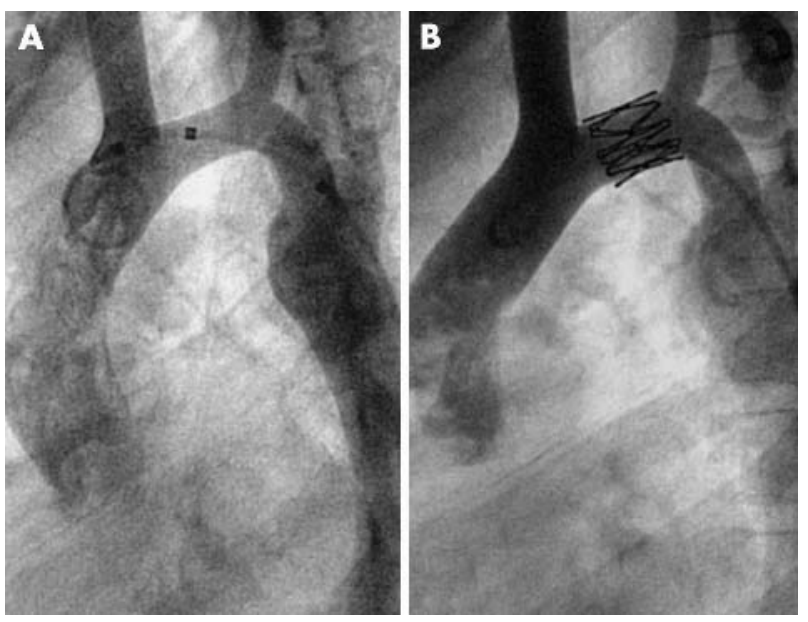

Figure 2 The shortest stent in this series was an $11 \mathrm{~mm}$ stent in the transverse aortic arch of an 8 year old boy. (A) Before implantation; (B) after implantation.

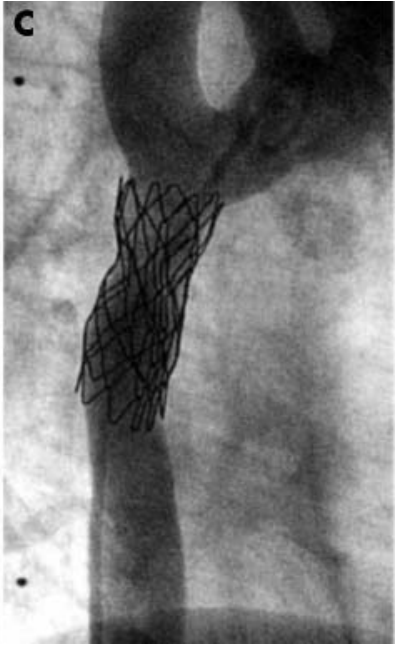

Figure 1 Implantation of a $39 \mathrm{~mm}$ covered Cheatham platinum (CP) stent for the treatment of subatretic aortic coarctation. (A) Composite of two frames of the same angiogram (early and late phase). The procedure was performed in two steps: (B) firstly, the stent was implanted with only moderate dilatation of the subatretic area;

(C) then after six months the stent was definitively dilated to completely relieve the stenosis.

All patients received heparin $100 \mathrm{IU} / \mathrm{kg}$ body weight before the intervention and $400 \mathrm{IU} / \mathrm{kg}$ body weight/day for the next 48 hours. Aspirin (2-3 mg/kg body weight/day) was recommended for six months. Patients with a TCPC received warfarin to an international normalised ratio (INR) between 2 and 3 as they had before the intervention.

\section{Follow up}

The postinterventional survey was undertaken by clinical evaluation, non-invasive blood pressure measurements, echocardiography, computed tomography, or repeat catheterisation. Special attention was directed to the femoral artery in children with coarctation and weighing less than $20 \mathrm{~kg}$. Repeated duplex sonography of the groins was performed to document the integrity of the vessels at discharge and during follow up.

\section{RESULTS}

In total, 60 stents were implanted in 53 patients (table 1). In 15 patients the procedure was performed in two steps: first the stent was implanted with only moderate dilatation of the stenotic vessel segment (fig 1B); then, after three to six months, the stent was definitively dilated (fig lC). Seven patients are awaiting the second dilatation. All stents were
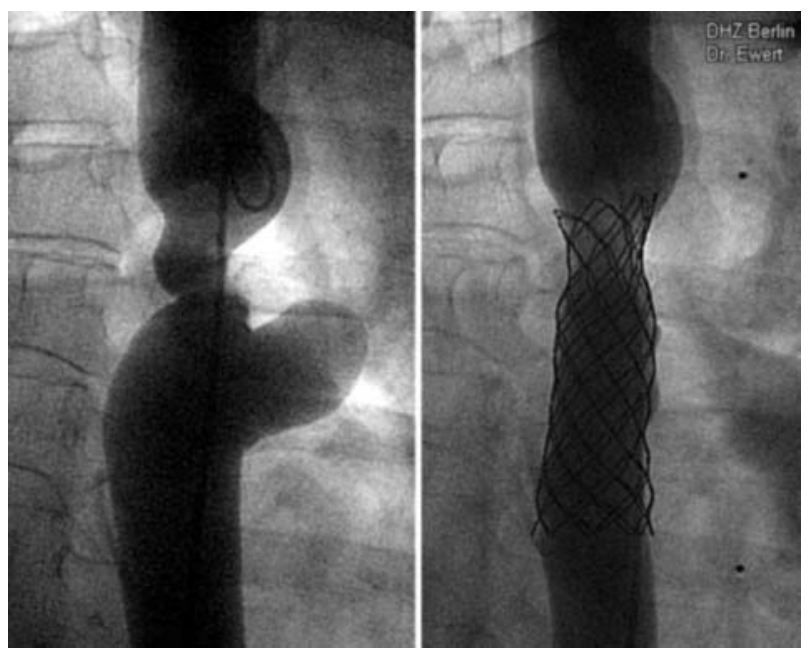

Figure 3 The largest stent used in this series was an $80 \mathrm{~mm}$ covered stent in a patient with recoarctation and aneurysm 30 years after surgery. (A) Before implantation; (B) after implantation. 

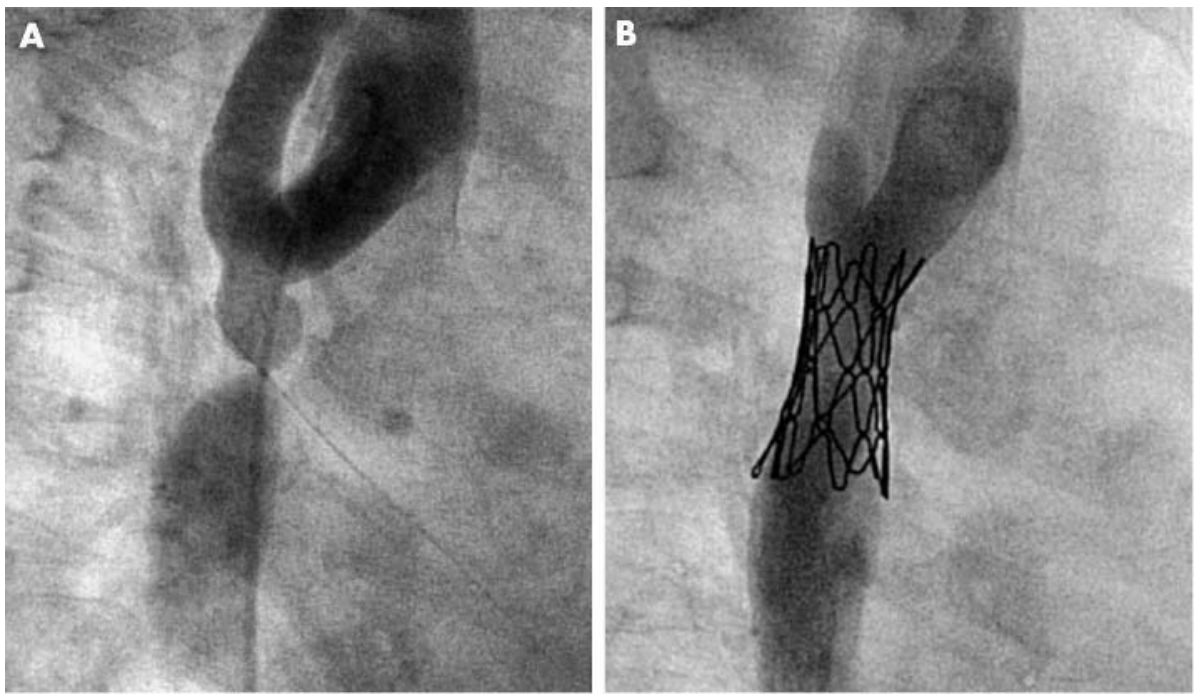

Figure 4 (A) Subatretic aortic coarctation in a 3 year old child weighing $14 \mathrm{~kg}$. (B) Balloon dilatation did not achieve sufficient pressure reduction, so that a $22 \mathrm{~mm} \mathrm{CP}$ stent on a $10 \mathrm{~mm}$ balloon was implanted, which led to a reduction of the pressure gradient from $60 \mathrm{~mm} \mathrm{Hg}$ to $5 \mathrm{~mm} \mathrm{Hg}$.

placed in the target lesions without stent dislocation during implantation or thereafter. Stent lengths ranged from 11$80 \mathrm{~mm}$ (figs 2 and 3). The dilated diameter was from 8$25 \mathrm{~mm}$. In children shorter stents were implanted than in adults.

\section{Coarctations and pulmonary arteries}

Thirty seven stents were placed into coarctations (fig 4): native coarctations (18), recoarctations after surgery (nine), after balloon dilatation (seven), or after stent implantation (three). The youngest patient was 2.5 years old and the lowest body weight was $12 \mathrm{~kg}$. Eleven coarctations were treated with 12 covered stents (fig l) because of the severity of the lesion (10), to the presence of an aneurysm (one) (fig 3), or to a stent fracture (1). ${ }^{26}$

In pulmonary arteries, three stents were placed in native lesions (fig 5) and 14 were placed in stenoses after surgery. Arterial pressure gradients dropped from $33 \mathrm{~mm} \mathrm{Hg}$ (range 20-80 $\mathrm{mm} \mathrm{Hg}$ ) to $5 \mathrm{~mm} \mathrm{Hg}$ (range 0-10 $\mathrm{mm} \mathrm{Hg}$ ).

\section{Caval veins and extracardiac conduits}

Six stents were placed in caval veins and extracardiac conduits (fig 6). Pressure gradients dropped from $4 \mathrm{~mm} \mathrm{Hg}$ (range 4-20 $\mathrm{mm} \mathrm{Hg}$ ) to $0 \mathrm{~mm} \mathrm{Hg}$ (range 0-3 $\mathrm{mm} \mathrm{Hg}$ ). For the patient in whom the stent created a communication between the extracardiac conduit and right atrium a $12 \mathrm{~mm}$ diameter was chosen with a balloon of corresponding size.

During the follow up period of 12 months (1-30 months) two patients died of unrelated causes. Twenty four patients underwent computed tomography or magnetic resonance imaging 4-12 weeks after stent implantation. No dissections or aneurysm formations were seen in any of these patients.

There were three stent fractures at the welds in this series, experienced in cases of severe stenosis with strong mechanical forces acting on the stent. All these stents were implanted before December 2002 and did not have reinforced welds. With the gold brazed stents no fractures have been detected so far in similar stenoses (fig 1).

\section{DISCUSSION}

Treating vessel stenosis in adult patients with congenital heart defects by stent implantation requires the stents to have specific properties. Since most lesions occur in the great vessels, stents have to be dilated to large diameters and still have to provide stability and radial force. Of course, in children it is advantageous to use such a stent, dilated to smaller diameters, ${ }^{2}{ }^{41425}$ providing the possibility of adapting the stent diameter by redilatation after somatic growth of the patient. Owing to the smaller anatomical size of children, however, the stent has to be available in a variety of shorter lengths, carrying the same potential of dilatability to larger
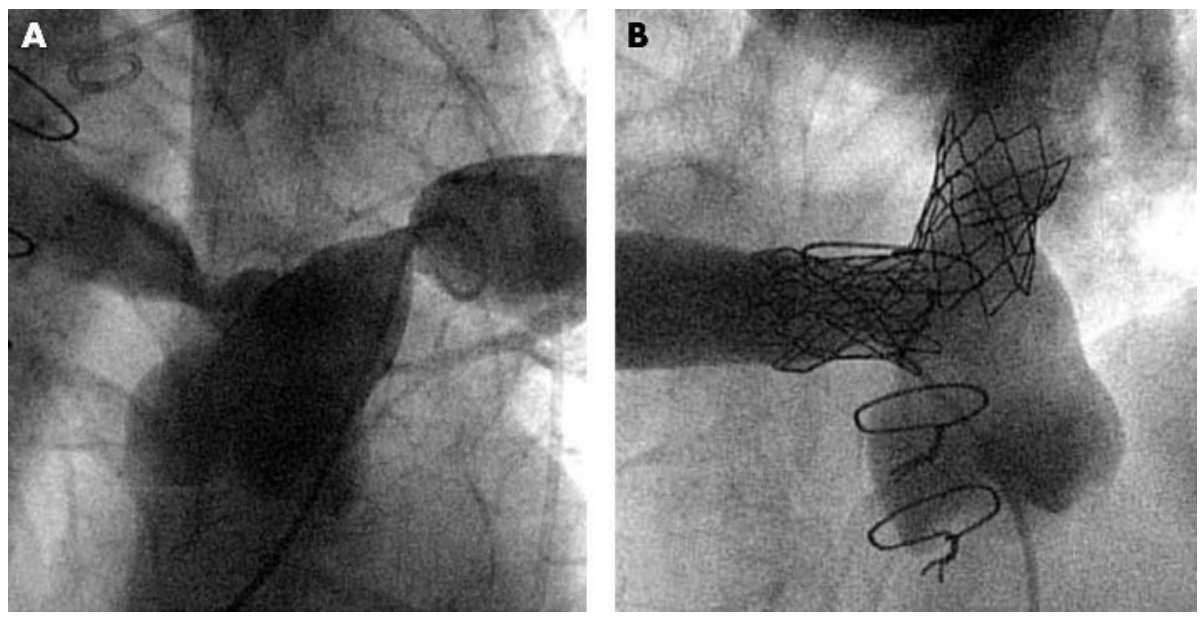

Figure 5 (A) Severe stenoses of right and left pulmonary arteries in an adult patient $\left(35^{\circ}\right.$ left anterior oblique, $36^{\circ}$ cranial). (B) Complete relief of the pressure gradients after consecutive implantation of two CP stents (8 zig, 28 $\mathrm{mm}$ each) and dilatation with a $16 \mathrm{~mm}$ balloon $\left(20^{\circ}\right.$ right anterior oblique, $45^{\circ}$ cranial). The smooth edges of the contralateral stent minimise the risk of balloon rupture. 

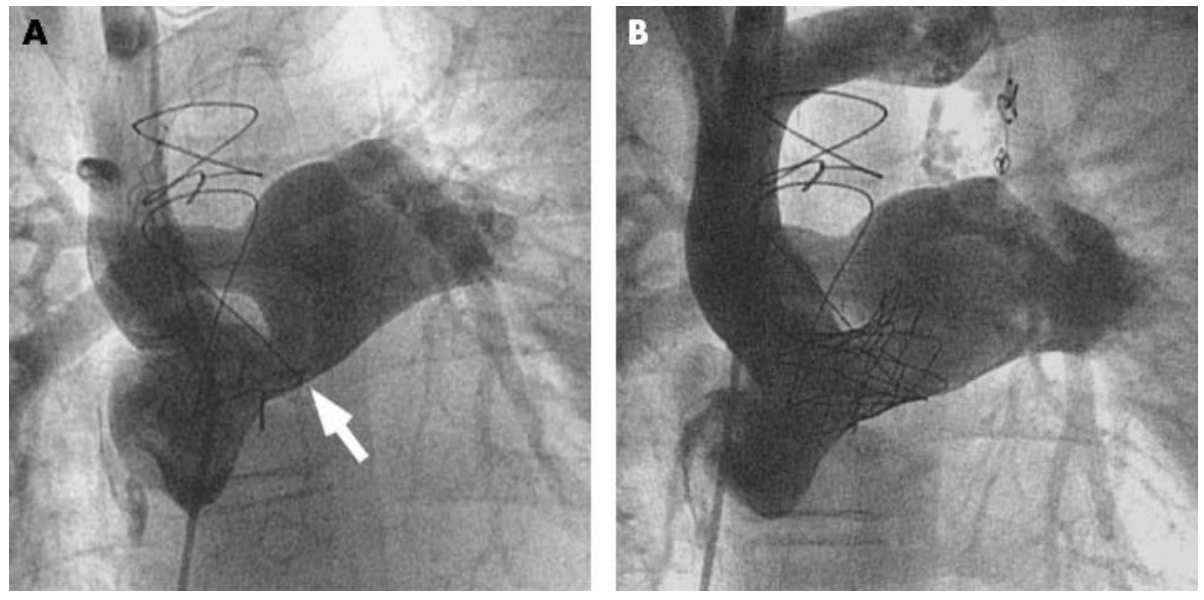

Figure 6 Patient with total cavopulmonary anastomosis by an intra-atrial tunnel and connection of the right atrial appendage to the pulmonary trunk. (A) A stenosis (arrow) at the atrial-arterial junction was treated with implantation of a $28 \mathrm{~mm}$ (B) CP stent dilated to a diameter of $22 \mathrm{~mm}$.

diameters without extreme foreshortening. The CP stent offers these features, which will probably be important in 18 of the patients in this study who have body weights less than $40 \mathrm{~kg}$ and have not yet reached their final body height. The availability of the stent in individual lengths enabled us to provide even small children with 8 zig stents of short length (fig 4). A variety of lengths is advantageous in adults, as we used stents from $22-80 \mathrm{~mm}$.

Stents were redilated in eight patients, in each case as a planned second dilatation to yield the definitive diameter six months after implantation. These stents were redilated without any complications and with good results as was expected from the behaviour of other stents used in congenital heart disease. ${ }^{27-31}$ Thus, we hope to obtain similar results after redilatation at a later stage when this becomes necessary in the paediatric patients because of their somatic growth.

The availability of the stent in a covered version, in our opinion, seems to be especially useful in very narrow stenotic vessels. The cover may provide the extremely stressed vessel area with an additional seal to avoid vessel dissection and bleeding. ${ }^{26}$ Furthermore, it may offer a solution for the combination of stenosis and vessel aneurysm by stenting the stenosis and covering the aneurysm (fig 3). Of course, the coverage of side branches has to be taken into consideration. In extreme coarctations the coverage may seal the orifices of collaterals that meet the descending aorta directly beneath the coarctation. We did not consider this disadvantageous as far as the stenosis is eliminated by the stent.

A disadvantage of the stent is the necessity of sheaths 2 French larger than the implantation balloon and even 3 French larger if the stent carries a PTFE cover. It is difficult to crimp the stent to smaller diameters than 8 to 9 French.
Although this may be of minor concern in a venous access site, it may be important in the case of the femoral arteries. In adults and children over $30 \mathrm{~kg}$ body weight, however, the use of a suture device before the introduction of the large implantation sheath has practically eliminated any problematic bleeding after the procedure. For small children no suitable suture device is available. Our benchmark in this study was $25 \mathrm{~kg}$ body weight. There was only one patient with a body weight below $30 \mathrm{~kg}$ (namely $28 \mathrm{~kg}$ ), in whom we used the Perclose stitch. Whether $25 \mathrm{~kg}$ is a justified limit to the use of this device is beyond the scope of this study. To avoid damage at the arterial access site we were anxious to shorten the time the large sheath remained in the vessel as much as possible and to take special care after removal of the sheath. Well advised, minimal but effective manual compression was applied for several minutes and then the patient was observed closely with no compression for about one hour. A pressure dressing was then applied given that a good pulse was palpable at the feet. The duplex sonography at discharge and at follow up showed unrestricted flow (fig 7) in each of these patients.

Three stents were fractured at the welds in cases of very high mechanical stress. Two of them affected singular struts without any dislodgment or mechanical instability of the stent. These patients were followed up by fluoroscopy at regular time intervals. The third, covered stent broke completely within six months after implantation. A second covered stent with reinforced gold brazed welds was implanted in the first one and resolved the stenosis. The latest follow up after 16 months showed stable conditions. ${ }^{26}$ We did not find any further fractures after the stents were manufactured with gold brazed welds beginning in December 2002, despite use of the stent in similar cases of high
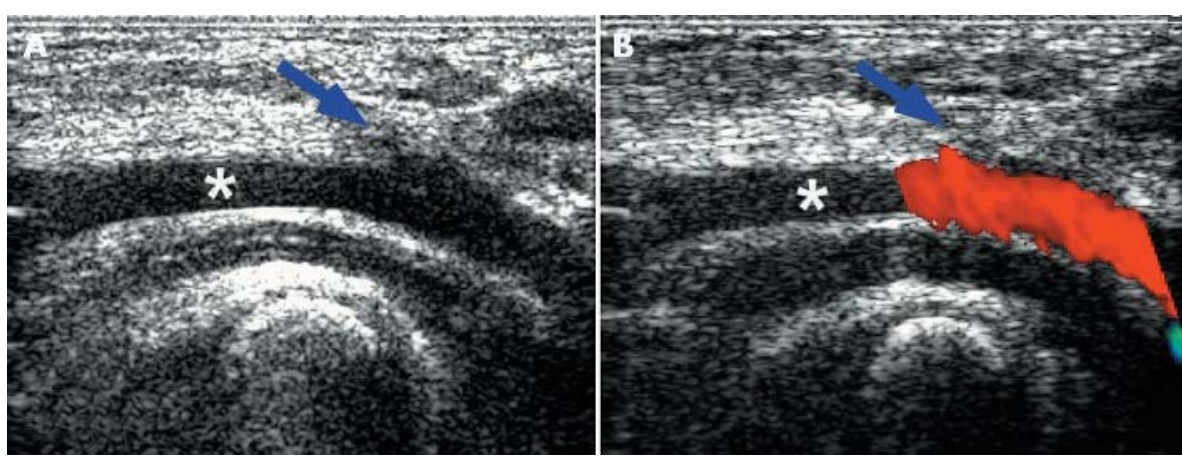

Figure 7 Sonography of the femoral artery (*) of a 2.5 year old boy with a body weight of $15 \mathrm{~kg}$ three days after implantation of a CP stent through a 9 French sheath. (A) The access site can be seen (blue arrow) but with no anatomical stenosis. (B) Colour Doppler showing laminar unobstructed flow across the vessel. 
mechanical strain (fig 1). Whether the new design will solve this problem, which has also been described for other stents, ${ }^{32}{ }^{33}$ will need to be elucidated in the future.

After a rather short follow up period of 12 months (range 1-30 months), we have seen no signs of restenosis by intima proliferation in any of our patients. So far, no dissections and no aneurysms at the implantation site of any stent have occurred, even in patients with subatretic vessels. We hope that the as yet theoretical advantage of the atraumatic edges of the stent, the frequent use of a balloon in balloon system to avoid excessive flaring during implantation, the PTFE cover in very severe stenosis, and the two step procedure in these lesions will help to maintain these good results over time.

Of course, one may argue that in the majority of cases an alternative stent already available on the market could have been used equally well. However, we feel that the CP stent contributes a degree of predictability, safety, confidence, and comfort to the procedures if one stent family can be used in a large range of indications.

Owing to its maximum expandable diameter of $25 \mathrm{~mm}$ combined with its variability in length from $11-50 \mathrm{~mm}$ and more, the CP stent is suitable for the treatment of vessel stenosis in congenital heart diseases from childhood to adulthood. The option of a PTFE cover can be advantageous for the treatment of very severe stenosis. Whether stent fractures can be prevented by the new design with gold brazed welds, and whether the good results achieved with the $\mathrm{CP}$ stent in this study will be stable in the long term, need to be investigated in future follow up.

\section{ACKNOWLEDGEMENTS}

We are grateful to Mrs Anne Gale for revision of the manuscript.

\section{Authors' affiliations}

P Ewert, S Schubert, B Peters, H Abdul-Khaliq, N Nagdyman, P E Lange, Abteilung für Angeborene Herzfehler, Deutsches Herzzentrum Berlin, Berlin, Germany

\section{REFERENCES}

1 O'Laughlin MP, Perry SB, Lock JE, et al. Use of endovascular stents in congenital heart disease. Circulation 1991;83:1923-39.

2 O'Laughlin MP, Slack MC, Grifka RG, et al. Implantation and intermediateterm follow-up of stents in congenital heart disease. Circulation 1993;88:605-14.

3 Schaffer Al. Coarctation hypertension is renovascular, modified by ambulation: coarctation hypertension renovascular variant. J Clin Hypertens 1986;2:69-78.

4 Okubo M, Benson LN. Intravascular and intracardiac stents used in congenital heart disease. Curr Opin Cardiol 2001;16:84-91.

5 Rutledge JM, Mullins CE, Nihill MR, et al. Initial experience with intratherapeutics IntraStent DoubleStrut LD stents in patients with congenital heart defects. Catheter Cardiovasc Interv 2002;56:541-8.

6 Diethrich EB, Heuser RR, Cardenas JR, et al. Endovascular techniques in adult aortic coarctation: the use of stents for native and recurrent coarctation repair. J Endovasc Surg 1995;2:183-8.
7 Bulbul ZR, Bruckheimer E, Love JC, et al. Implantation of balloon-expandable stents for coarctation of the aorta: implantation data and short-term results. Cathet Cardiovasc Diagn 1996;39:36-42.

8 Ebeid MR, Prieto LR, Latson LA. Use of balloon-expandable stents for coarctation of the aorta: initial results and intermediate-term follow-up. J Am Coll Cardiol 1997;30:1847-52.

9 Gunn J, Cleveland T, Gaines P. Covered stent to treat co-existent coarctation and aneurysm of the aorta in a young man. Heart 1999;82:351

10 Pihkala J, Pedra CA, Nykanen D, et al. Implantation of endovascular stents for hypoplasia of the transverse aortic arch. Cardiol Young 2000;10:3-7.

11 Thanopoulos BD, Hadjinikolaou L, Konstadopoulou GN, et al. Stent treatment for coarctation of the aorta: intermediate term follow up and technical considerations. Heart 2000;84:65-70.

12 De Giovanni JV. Covered stents in the treatment of aortic coarctation. J Interv Cardiol 2001;14:187-90.

13 Hamdan MA, Maheshwari S, Fahey JT, et al. Endovascular stents for coarctation of the aorta: initial results and intermediate-term follow-up. J Am Coll Cardiol 2001;38:1518-23.

14 Ewert $\mathrm{P}$, Berger $\mathrm{F}$, Kretschmar $\mathrm{O}$, et al. [Stent implantation as therapy of first choice in adults with coarctation]. Z Kardiol 2003;92:48-52.

15 Forbes T, Matisoff D, Dysart J, et al. Treatment of coexistent coarctation and aneurysm of the aorta with covered stent in a pediatric patient. Pediatr Cardiol 2003;24:289-91.

16 Macdonald S, Thomas SM, Cleveland TJ, et al. Angioplasty or stenting in adult coarctation of the aorta? A retrospective single center analysis over a decade. Cardiovasc Intervent Radiol 2003;26:357-64.

17 Piechaud JF. Stent implantation for coarctation in adults. J Interv Cardiol 2003;16:413-8.

18 Tyagi S, Singh S, Mukhopadhyay S, et al. Self- and balloon-expandable stent implantation for severe native coarctation of aorta in adults. Am Heart $J$ 2003; 146:920-8

19 Zabal C, Attie F, Rosas M, et al. The adult patient with native coarctation of the aorta: balloon angioplasty or primary stenting? Heart 2003;89:77-83.

20 Fogelman R, Nykanen D, Smallhorn JF, et al. Endovascular stents in the pulmonary circulation: clinical impact on management and medium-term follow-up. Circulation 1995;92:881-5.

21 Moore JW, Spicer RL, Perry JC, et al. Percutaneous use of stents to correct pulmonary artery stenosis in young children after cavopulmonary anastomosis. Am Heart J 1995; 130:1245-9.

22 Hijazi ZM, al-Fadley F, Geggel RL, et al. Stent implantation for relief of pulmonary artery stenosis: immediate and short-term results. Cathet Cardiovasc Diagn 1996;38:16-23.

23 Spadoni I, Giusti S, Bertolaccini P, et al. Long-term follow-up of stents implanted to relieve peripheral pulmonary arterial stenosis: hemodynamic findings and results of lung perfusion scanning. Cardiol Young 1999;9:585-91.

24 Tomita H, Yazaki S, Kimura K, et al. Potential goals for the dimensions of the pulmonary arteries and aorta with stenting after the Fontan operation. Catheter Cardiovasc Interv 2002;56:246-53.

25 Cheatham JP. Stenting of coarctation of the aorta. Catheter Cardiovasc Interv 2001;54:112-25.

26 Ewert P, Abdul-Khaliq H, Peters B, et al. Transcatheter therapy of long extreme subatretic aortic coarctations with covered stents. Catheter Cardiovasc Interv 2004;63:236-9.

27 Ing FF, Grifka RG, Nihill MR, et al. Repeat dilation of intravascular stents in congenital heart defects. Circulation 1995;92:893-7.

28 Duke C, Rosenthal E, Qureshi SA. The efficacy and safety of stent redilatation in congenital heart disease. Heart 2003;89:905-12.

29 Morrow WR, Palmaz JC, Tio FO, et al. Re-expansion of balloon-expandable stents after growth. J Am Coll Cardiol 1993;22:2007-13.

30 Schneider MB, Zartner P, Duveneck K, et al. Various reasons for repeat dilatation of stented pulmonary arteries in paediatric patients. Heart 2002;88:505-9.

31 Shaffer KM, Mullins CE, Grifka RG, et al. Intravascular stents in congenital heart disease: short- and long-term results from a large single-center experience. J Am Coll Cardiol 1998;31:661-7.

32 Knirsch W, Haas NA, Lewin MA, et al. Longitudinal stent fracture 11 months after implantation in the left pulmonary artery and successful management by a stent-in-stent maneuver. Catheter Cardiovasc Interv 2003;58:1 16-8.

33 Ledesma M, Jauregui R, Ceron CK, et al. Stent fracture after stent therapy for aortic coarctation. J Invasive Cardiol 2003;15:719-21. 